Www.jmscr.igmpublication.org
Impact Factor 3.79

ISSN (e)-2347-176x

crossref DOI: http://dx.doi.org/10.18535/jmscr/v3i10.03 \author{
IGM Publication \\ Journal Of Medical Science And Clinical Research \\ An Official Publication of IGM Publication \\ (2)
}

\title{
Study of Thyroid Abnormalities in Psychiatric Out Patients with Depression At A Tertiatry Care Centre in Central India
}

\author{
Authors \\ Dr Parul Nema, Dr C V Kulkarni, Dr Meena Mittal, Dr Vishnu K Gupta, \\ Dr Rangbhulan Razdar \\ Corresponding Author
}

Dr Parul Nema

Dept. Pathology, Post Resident

Email:drparulnema@gmail.com

\begin{abstract}
Introduction Thyroid hormones have a profound influence on the human brain and behaviour, and the interrelationship between thyroid dysfunction and psychiatric disturbances has been well documented. Up to one-third of psychiatric patients may demonstrate thyroid function test abnormalities that do not always reflect true thyroid disease, but rather are a manifestation of secondary effects on one or more levels of the hypothalamic-pituitary-thyroid (HPT) axis.

Materials And Methods Samples collected from 69 O.P.D. patients who are newly diagnosed cases of depression, not on medication and more than 18 yrs of age. Patient having thyroid disorder or on medication affecting thyroid function are excluded from study. Serological test Thyroid Stimulating Hormone (TSH) Test, Total T4/ Total Thyroxine, Total T3 / Total Triiodothyronine are done for identifying thyroid function abnormality in psychiatric patients.

Results- Out of 69 psychiatric out patients with clinical diagnosis of depression investigated for thyroid abnormalities, Males were 37 \& Female were 32. The mean age of the study subjects was 35.23 yr. Abnormal thyroid function test was observed in 26 out of 69 (37.6\%) patients.

Conclusion- As psychiatric disturbances may be a manifestation of thyroid disease, clinical assessment of physical signs and symptoms of thyroid disease should be a routine element of psychiatric evaluation. If there is suspicion for thyroid disease, measurement of TSH with a sensitive method should be the first test obtained. Key Words- Brain, HPT-axis, T3, T4, TSH, interrelationship.
\end{abstract}

\section{Introduction}

Thyroid hormones have a profound influence on the human brain and behavior, and the interrelationship between thyroid dysfunction and psychiatric disturbances has been well documented. Up to one-third of psychiatric patients may demonstrate thyroid function test abnormalities that do not always reflect true thyroid disease, but rather are a manifestation of secondary effects on one or more levels of the hypothalamic-pituitary-thyroid (HPT) axis. Originally termed the euthyroid sick syndrome, this phenomenon is now more commonly referred to as "non-thyroidal illness."

Nonthyroidal illness is characterized by the presence of altered thyroid function parameters 
that are not considered indicative of actual thyroid disease but rather occur as a response to underlying systemic or acute psychiatric illness. This syndrome may be seen in a variety of systemic illnesses and stress states, as well as in psychiatric illness. $^{3}$

The prevalence of mood and anxiety disorders is higher in patients with thyroid dysfunction ${ }^{6}$, thyroid status predicts treatment response in major depression and bipolar disorder ${ }^{7}$, augmentation with thyroid hormone has therapeutic efficacy in treatment-resistant depression ${ }^{8}$, and additionally, thyroid hormone receptors are localized to limbic structures implicated in regulation of mood ${ }^{9}$. There is limited literature on the rates of thyroid dysfunction among patients with major psychiatric disorders in the Indian population.

The term "thyroid dysfunction" refers to abnormalities in laboratory test parameters of thyroid hormonal status, namely serum TSH (thyroid stimulating hormone), T3 (triiodothyroxine), \& T4 (L-thyroxine). ${ }^{5}$

\section{Materials and methods}

The prospective study is conducted at M.G.M. Medical College and M.Y. Hospital, Indore, a tertiary-care, Government Hospital in Psychiatric O.P.D. in year 2013-2014. The study protocol is approved by the M.G.M. Medical College Institutional Ethics Review Board (IERB). The patients are assigned an ICD- $10^{37}$ diagnosis based on a clinical interview and diagnostic consensus between two consultant psychiatrists. The focus of the analysis is to examine thyroid status in patients with depression disorders.

Samples are collected from Psychiatric O.P.D. patients-

\section{Inclusion criteria are-}

1. Newly diagnosed cases not on medication.

2. Patient should be more than 18 yrs of age.

\section{Exclusion criteria are-}

1. Patient having thyroid disorder.

2. Patient on medication affecting thyroid function.
Sample collection consent is taken from the patients or first degree relative of the mentally ill patients.

\section{Specimen collection and preparation}

1. Serum is the recommended sample type for this assay.

2. Samples were collected observing universal precautions for venipuncture.

3. Samples were allowed to clot for 1 hour before centrifugation.

4. Grossly hemolytic, lipemic or turbid samples were avoided.

5. Prior to use, specimens were capped and stored at $2-8^{\circ} \mathrm{C}$ (upto $48 \mathrm{hrs}$ )

The assays of TSH, T3, and T4 are done by the Chemilumniscence (CLIA) method using Autobio LUMO microplate luminometer. Reagents were obtained from Autobio. The sensitivity and range for the assays were as follows:

$\mathrm{T} 3=0.1 \mathrm{ng} / \mathrm{ml}$ (range $=0.1-8 \mathrm{ng} / \mathrm{ml}) ; \mathrm{T} 4=0.5 \mu \mathrm{g} / \mathrm{dl}$ (range $=0.5-30 \mu \mathrm{g} / \mathrm{dl}$ ); TSH $=0.003 \mu \mathrm{IU} / \mathrm{ml}$ (range $=$ $0.01-100 \mu \mathrm{IU} / \mathrm{ml}$ )

Following serological test are done for identifying thyroid function abnormality in psychiatric patients:

1. Thyroid Stimulating Hormone (TSH) Test

$$
\text { Reference Range - 0.5-5.0 } \mu \mathrm{IU} / \mathrm{ml}
$$

2. Total T4/ Total Thyroxine Reference Range- 5.5-12.5 $\mu \mathrm{g} / \mathrm{dl}$

3. Total T3 / Total Triiodothyronine Reference Range 0.8-2.0 ng/ml

\section{RESULTS}

Results of 69 patients tested for thyroid function test were recorded. Male $=37 \&$ Female $=32$. The mean age of the study subjects was $35.23 \mathrm{yr}$. Hypothyroidism was diagnosed when the TSH levels are more than normal reference range $(>5.0 \mu \mathrm{IU} / \mathrm{ml})$. Hyperthyroidism was diagnosed when the TSH values are less than normal reference range $(<0.5 \mu \mathrm{IU} / \mathrm{ml})$. 


\section{Thyroid dysfunction in patients with depression}

The study revealed a significant association of the endocrinopathy with the diagnostic group of Depression. There were 69 patients with depression. (Table No. 1) 26 out of the $69(37.68 \%)$ patients with depression had abnormality in one or more parameter of thyroid function test. Hypothyroidism was observed in 8 out of 26 (30.76\%) patients and Hyperthyroidism was observed in 4 out of $26(15.3 \%)$ patients of depression with abnormal thyroid function test. Non specific alterations in the TFT are much more common in patients with depression and are seen in 14 out of 26 patients with abnormal TFT. As these patients are clinically euthyroid these patients represent Nonthyroidal illness or Euthyroid Sick Syndrome.
Gender effect- Abnormal thyroid hormonal levels are more common in females than male patients with depression. 12 out of 37 males (32.4\%) were having abnormal thyroid hormone levels while 14 out of $32(43.7 \%)$ females having abnormal thyroid function test. (Table No. 2)

Age distribution of abnormal TFT in patients suffering from depression-

Most of the patients in the study group belonged to the age group of 26-35yrs followed by $18-25 \mathrm{yrs}$ i.e. young adults. However thyroid function test abnormalities were more common in older age group of $46-55 \mathrm{yrs}$ in which 5 out of $8(62.5 \%)$ patients show abnormal thyroid function test. While age group of 26-35 yrs in which 8 out of 22 (36\%) patients with second highest number of abnormal thyroid function test were observed. (Table No.3)

Table No. 1 Diagnosis wise distribution of Abnormal TFT

\begin{tabular}{|l|c|c|c|c|c|}
\hline Diagnosis & $\begin{array}{c}\text { No. of } \\
\text { Patients }\end{array}$ & $\begin{array}{c}\text { Abnormal } \\
\text { TFT }\end{array}$ & $\begin{array}{c}\text { Hypo- } \\
\text { thyroidism }\end{array}$ & $\begin{array}{c}\text { Hyper- } \\
\text { thyroidism }\end{array}$ & $\begin{array}{c}\text { Nonspecific } \\
\text { findings }\end{array}$ \\
\hline Depression & 69 & 26 & 8 & 4 & 14 \\
\hline
\end{tabular}

Table No. 2 Sex distribution of abnormal TFT

\begin{tabular}{|l|c|c|}
\hline Sex & No. Of Patients & Abnormal TFT \\
\hline Male & 37 & 12 \\
\hline Female & 32 & 14 \\
\hline
\end{tabular}

Table No. 3 -Age distribution of abnormal TFT in Psychiatric patients

\begin{tabular}{|l|c|c|}
\hline & Depression & \\
\hline Age interval & Total & Abnormal TFT \\
\hline $\mathbf{1 8 - 2 5}$ & 17 & 7 \\
\hline $\mathbf{2 6 - 3 5}$ & 22 & 8 \\
\hline $\mathbf{3 6 - 4 5}$ & 19 & 5 \\
\hline $\mathbf{4 6 - 5 5}$ & 8 & 5 \\
\hline $\mathbf{5 6 - 6 5}$ & 3 & 1 \\
\hline
\end{tabular}

\section{Discussion}

Our results indicated that thyroid abnormalities were present in patients with depression disorders in psychiatric O.P.D. population of a tertiary-care hospital. Thyroid dysfunction in Depression disorder seen in our study was $(37.68 \%)$ which was higher than that shown by Rajiv Radhakrishnan et al $(25.41 \%)^{5}$ Bartalena et al $^{11}$ $(32 \%)$ and that of Cassidy et $\mathrm{al}^{12}(11.51 \%)$.
Among the general population in India, the rates of thyroid dysfunction are, clinical hypothyroidism=3.9 per cent, subclinical hypothyroidism $=9.4$ per cent $^{10}$. Hypothyroidism was seen 8 out of $69(11.5 \%)$ psychiatric patients of the study group population. Abnormal thyroid hormonal levels are more common in females $(43.7 \%)$ than male $(32.4 \%)$ patients with depression. 
Another significant finding is that thyroid hormone abnormalities may represent nonthyroidal illness such as "euthyroid sick syndrome" and "euthyroid hyperthyroxinemia" which are a response to chronic systemic illness. The prevalence of euthyroid sick syndrome ranges from 7 to 33 per cent in psychiatric inpatients ${ }^{1,13}$ while euthyroid hyperthyroxinemia is thought to be more common in mood disorders ${ }^{14}$. Although it is difficult to distinguish nonthyroidal illness from true thyroid dysfunction in euthyroid subjects, the TSH level in euthyroid sick syndrome is upto 15$20 \mu \mathrm{IU} / \mathrm{ml}^{15}$. Severe thyroid dysfunction may mimic almost any psychiatric symptom profile. $^{16,17}$

It has been assumed that specific psychiatric disorders may be associated with alterations in thyroid functioning, and subclinical hypothyroidism has been suspected of being a risk factor for depression. ${ }^{18,19}$ This hypothesis is supported by the fact that, in selected cases, thyroid hormone therapy has proved useful in the management of refractory depression. ${ }^{20}$ The close relationship of thyroid economy and cognitive function has interested clinicians and researchers since the possible association between thyroid functioning and behavior was first described by Parry $^{21}$ and Graves. ${ }^{22}$ Asher's findings show that thyroid hormone deficiency may lead to depression and psychosis and may be reversed by desiccated thyroid administration. ${ }^{16}$ Many studies on hypothalamic-pituitary-thyroid (HPT) system have suggested that thyroid hormones play an important role in the pathophysiology of mood disorders. ${ }^{2324}$ Thyroid hormones may interact with neurotransmitter systems and intracellular mechanisms and are capable of modulating the phenotypic expression of major affective illnesses, ${ }^{23,24}$ depressive and bipolar disorders in particular. Studying the HPT axis, investigators have found abnormal TSH response to TRH stimulation in depressed patients. ${ }^{27,29-31}$ The peak response was blunted in $25 \%$ to $30 \%$ of patients ${ }^{32}$ and exaggerated in $10 \% .{ }^{33}$ Elevated levels of cerebrospinal fluid (CSF) TSH have also been reported in depressed patients. ${ }^{34}$ Most depressed patients are euthyroid, although subclinical hypothyroidism can be seen in approximately $15 \%$ of depressed patients. ${ }^{25}{ }^{26}$ Subclinical hypothyroidism may be a risk factor for depression in women. ${ }^{67}$ The time to recurrence of depressive episodes was found to be inversely correlated with serum $T_{3}$ but not $T_{4}$ levels in patients with unipolar depression. ${ }^{28}$ In this study raised serum triiodothyronine $\left(\mathrm{T}_{3}\right)$ level were significantly associated with depressive disorder group of patients with $\mathrm{p}$ value $<.002$. Thyroid measures in the low-normal or below-normal range seem to be relevant for the pathophysiology of bipolar disorders and may result in a less than optimal outcome ${ }^{37}$. Frye and colleagues ${ }^{35}$ reported an association of low levels of $\mathrm{T}_{4}$, within the normal range, with greater mood instability and depression severity during prophylactic lithium treatment in bipolar patients. Cole and colleagues $^{36}$ found poorer treatment response in bipolar patients with lower free $\mathrm{T}_{4}$ index values and higher TSH values within the normal range. Potential pathophysiologic factors contributing to hyperthyroxinemia in psychiatric patients include redistribution of $\mathrm{T}_{4}$ out of the tissues (particularly the liver), temporary pituitary thyrotroph resistance to $T_{4}$, or impairment of $T_{4}$ clearance ${ }^{38}$. There is some evidence suggesting that centrally mediated hypersecretion of TSH is present in these patients ${ }^{39}$ In the case of hypothyroxinemic nonthyroidal illness seen in acute psychiatric patients, inhibition of TSH secretion and impairment of normal feedback responses may be due to production of cytokines and other humoral or local factors. ${ }^{40,41}$

\section{Conclusion- In the present study-}

- 26 out of 69 psychiatric patients with depressive disorder show thyroid dysfunction, among which $30.7 \%$ patients show hypothyroidism, $15.3 \%$ patients show hyperthyroidism and $53.8 \%$ patients show non-specific alterations in concentration of iodothyronines (T3 or T4). 
- Patients with non-specific alterations in concentration of $\mathrm{T} 3$ or $\mathrm{T} 4$ belonged to the group of Nonthyroidal illness or Euthyroid Sick Syndrome. Nonspecific alterations of T3 and T4 were commonly seen in patients with Depression.

- Raised serum triiodothyronine $\left(\mathrm{T}_{3}\right)$ levels were significantly associated with depressive patients with $\mathrm{p}$ value $<0.002$. (T- Test)

- Abnormal thyroid hormonal levels are more common in females $(43.7 \%)$ than male $(32.4 \%)$ patients with depression.

- Hyperthyroidism was seen more commonly in male patients with depression than females.

Both excess and inadequate thyroid hormones can induce disturbances of behaviour that mimic depression, mania, and dementia. The neurocognitive impairments accompanying these dysfunctions are generally reversible following return to euthyroid status. Because psychiatric disturbances may be a manifestation of thyroid disease, clinical assessment of physical signs and symptoms of thyroid disease should be a routine element of psychiatric evaluation. As in the medical inpatient population, the decision to order thyroid screening should be made on an individual basis, and results should be interpreted with caution.

\section{References}

1. Anna L. Dickerman, M.D.; John W. Barnhill, M.D.et al Abnormal Thyroid Function Tests in Psychiatric Patients: A Red Herring? Am J Psychiatry 2012;169:127-133.

10.1176/appi.ajp.2011.11040631

2. Fardella $\mathrm{C}$, Gloger $\mathrm{S}$, Figueroa $\mathrm{R}$, et $\mathrm{Al}$ High prevalence of thyroid abnormalities in a Chilean psychiatric outpatient population Department of Endocrinology, Faculty of Medicine, Catholic University of Chile, Santiago. J Endocrinol Invest. $2000 \mathrm{Feb} ; 23(2): 102-6$.
3. Richard P. Levy, Jonathan B. Jensen, et al Serum thyroid hormone abnormalities in psychiatric disease Department of Psychiatry, University Hospitals of Cleveland Cleveland. OhioUSA Volume 30, issue 11, Nov 1981,pages 1060-1064.

4. Purandare KN, Wagle AC, Parker SR et al Psychiatric morbidity in patients with systemic lupus erythematosus. Department of Psychiatry, Fairfield Hospital, Hutchen QJM. 1999 May;92(5):283

5. Rajiv Radhakrishnan, Sam Calvinet al Thyroid dysfunction in major psychiatric disorders in a hospital based sample Indian J Med Res 138, December 2013, pp 888-893 Department of Psychiatry, St. Johns Medical College, Bangalore, India \& Department of Psychiatry, Yale School of Medicine, New Haven, CT, USA

6. Pla1cidi GP, Boldrini M, Patronelli A, Fiore E, Chiovato L, Perugi G, et al. Prevalence of psychiatric disorders in thyroid diseased patients. Neuropsychobiology 1998; 38 : 222-5.

7. Gitlin M, Altshuler LL, Frye MA, Suri R, Huynh EL, Fairbanks 2. L, et al. Peripheral thyroid hormones and response to selective serotonin reuptake inhibitors. $J$ Psychiatry Neurosci 2004; 29 : 383-6.

8. Carvalho AF, Machado JR, Cavalcante JL. Augmentation 3. strategies for treatmentresistant depression. Curr Opin Psychiatry 2009; $22: 7-12$.

9. Bauer $M$, London ED, Silverman DH, Rasgon N, Kirchheiner 4. J, Whybrow PC. Thyroid, brain and mood modulation in affective disorder: insights from molecular research and functional brain imaging. Pharmacopsychiatry 2003; 36 (Suppl 3): S215-21.

10. Unnikrishnan AG, Menon UV. Thyroid disorders in India: 15. An epidemiological perspective. Indian $J$ Endocrinol Metab 2011; 15 (Suppl 2): S78-81. 
11. Bartalena L, Pellegrini L, Meschi M, Antonangeli L, Bogazzi 16. F, Dell'Osso L, et al. Evaluation of thyroid function in patients with rapid-cycling and non-rapidcycling bipolar disorder. Psychiatry Res 1990; $34: 13-7$.

12. Cassidy F, Ahearn EP, Carroll BJ. Thyroid function in mixed 17. and pure manic episodes. Bipolar Disord 2002; 4 : 393-7.

13. Nader S, Warner MD, Doyle S, Peabody CA. Euthyroid sick . syndrome in psychiatric inpatients. Biol Psychiatry 1996; 40 : 1288-93.

14. Lambert TJ, Davidson R, McLellan GH. Euthyroid hyperthyroxineaemia in acute psychiatric admissions. Aust $N \quad Z \quad J$ Psychiatry 1987; 21 : 608-12.

15. Chopra IJ. Clinical review 86: Euthyroid sick syndrome: is it a. misnomer? J Clin Endocrinol Metab 1997; 82 : 329-34.

16. Asher R. Myxoedematous madness. $\mathrm{Br}$ Med J 1949;9:555-62.

17. Brownlie BE, Rae AM, Walshe JW, Wells JE. Psychoses associated with thyrotoxicosis - 'thyrotoxic psychosis.' A report of 18 cases, with statistical analysis of incidence. Eur J Endocrinol 2000; 142:438-44.

18. Haggerty JJ Jr, Stern RA, Mason GA, Beckwith J, Morey CE, Prange AJ Jr. Subclinical hypothyroidism: A modifiable risk factor for depression? Am J Psychiatry 1993;150:508-10.

19. Oomen HA, Schipperijn AJ, Drexhage HA. The prevalence of affective disorder and in particular of a rapid cycling of bipolar disorder in patients with abnormal thyroid function tests. Clin Endocrinol (Oxf) 1996;45:215-23.

20. Sokolov STH, Levitt AJ, Joffe RT. Thyroid hormone levels before unsuccessful antidepressant therapy are associated with later response to T3 augmentation. Psychiatry Res 1997;69:203-6.
21. Parry CH. Collections From the Unpublished Writings of the Late C.H. Parry. Vol 2. London, UK: Underwoods; 1825.

22. Graves RJ. Newly observed affection of the thyroid gland in females. Lond Med Surg J. 1835;7:516-517.

23. Bauer MS, Whybrow PC, Winokur A. Rapid cycling bipolar affective disorder. I. Association with grade I hypothyroidism. Arch Gen Psychiatry. 1990;47(5):427-432.

24. Bauer M, Whybrow PC. Thyroid hormone, neural tissue and mood modulation. World J Biol Psychiatry. 2001;2(2):59-69.

25. Gold MS, Pottash AL, Extein I. Hypothyroidism and depression. Evidence from complete thyroid function evaluation. JAMA. 1981;245(19):1919-1922.

26. Haggerty JJ Jr, Prange AJ Jr. Borderline hypothyroidism and depression. Annu Rev Med. 1995;46:37-46.

27. Haggerty JJ Jr, Stern RA, Mason GA, Beckwith J, Morey CE, Prange AJ Jr. Subclinical hypothyroidism: a modifiable risk factor for depression? Am J Psychiatry. 1993;150(3):508-510.

28. Joffe RT,Thyroid hormone levels and recurrence of major depression. Am J Psychiatry. 2000;157(10):1689-1691.

29. Loosen PT, Prange AJ Jr. Serum thyrotropin response to thyrotropinreleasing hormone in psychiatric patients: a review. Am J Psychiatry. 1982; 139(4):405-416.

30. Bauer MS, Whybrow PC. Thyroid hormones and the central nervous system in affective illness: interactions that may have clinical significance. Integr Psychiatry. 1988;6:75-100.

31. Baumgartner A, Graf KJ, Kurten I, Meinhold H. The hypothalamic-pituitarythyroid axis in psychiatric patients and healthy subjects: Parts 1-4. Psychiatry Res. 1988;24(3):271-332. 
32. Loosen PT. The TRH-induced TSH response in psychiatric patients: a possible neuroendocrine marker. Psychoneuroendocrinology. 1985; 10(3):237-260.

33. Mason GA, Garbutt JC, Prange AJ. Thyrotropin-releasing hormone. In: Bloom, FE, Kupfer DJ, eds. Psychopharmacology: The Fourth Generation of Progress. New York, NY: Raven Press; 1995:493-503.

34. Banki CM, Bissette G, Arato M, Nemeroff CB. Elevation of immunoreactive CSF TRH in depressed patients. Am $J$ Psychiatry. 1988;145(12):1526-1531.

35. Frye MA, Denicoff KD, Bryan AL, et al. Association between lower serum free T4 and greater mood instability and depression in lithium-maintained bipolar patients. Am J Psychiatry. 1999;156 (12): 1909-1914.

36. 4 Cole DP, Thase ME, Mallinger AG, et al. Slower treatment response in bipolar depression predicted by lower pretreatment thyroid function. Am $J$ Psychiatry. 2002;159(1):116-121.

37. Andrea Pfennig, Mark A. Frye et al "The Mood Spectrum and HypothalamicPituitary-Thyroid Axis" Primary psychiatry vol.11 no.10 2004.

38. Cavalieri RR: The effects of nonthyroid disease and drugs on thyroid function tests. Med Clin North Am 1991; 75:27-39

39. Roca RP; Blackman MR; Ackerley MB; Harman SM; Gregerman RI: Thyroid hormone elevations during acute psychiatric illness: relationship to severity and distinction from hyperthyroidism. Endocr Res 1990; 16:415-447

40. Reichlin S: Neuroendocrine immune interactions. N Engl J Med 1993; 329:1246-1253

41. Docter R; Krenning EP; de Jong M; Hennemann G: The sick euthyroid syndrome: changes in thyroid hormone serum parameters and hormone metabolism. Clin Endocrinol (Oxf) 1993; 39:499-518 